\title{
Genistein contributes to cell cycle progression and regulates oxidative stress in primary culture of osteoblasts along with osteoclasts attenuation
}

\author{
Sahabjada Siddiqui ${ }^{1,2^{*}}$ (D) Abbas Ali Mahdi ${ }^{3}$ and Md Arshad $2,4^{*}$
}

\begin{abstract}
Background: The present study was designed to examine the role of isoflavone genistein (GS) on bone formation, regulating oxidative stress and cell cycle in primary osteoblasts, as well as attenuation of osteoclast formation.

Methods: Primary calvaria osteoblasts were isolated from 2 to 3 days old neonatal rat pups $(n=6-8)$ of Sprague Dawley rats. Osteoblasts were incubated with varying concentrations of GS and different assays viz. cell proliferation, differentiation, calcium deposition, cell cycle progression, antioxidant ability, and osteogenic gene expression were performed. Tartrate-resistant acid phosphatase (TRAP) staining and immunolocalization of cathepsin $\mathrm{K}$ protein were assessed in bone marrow-derived osteoclasts.

Results: Results revealed that GS markedly induced cell growth and osteoblast differentiation depending upon dose. The fluorescent dye DCFH-DA staining data proved the antioxidant ability of GS, which reduced the $\mathrm{H}_{2} \mathrm{O}_{2^{-}}$ induced intracellular oxidative stress in osteoblasts. Quantitative real-time PCR analysis revealed that GS treatment upregulated the expression of osteoblastic genes of Runt-related transcription factor 2 (Runx2), bone morphogenetic proteins 2 (BMP2), and osteocalcin. Immunolocalization of BMP2 also indicated the osteogenic efficacy of GS. Furthermore, TRAP staining and cathepsin K expression depicted that GS inhibited multinucleated osteoclasts formation.

Conclusions: In conclusion, GS isoflavone might impart protective effects against oxidative stress-induced bone loss and thus, could maintain skeletal growth.
\end{abstract}

Keywords: Cell cycle, Isoflavone, Oxidative stress, Primary bone cells

\section{Background}

The balance between bone formation, bone resorption, proliferation, and apoptosis helps to maintain bone mass nearly constant [1]. An imbalance between bone resorption and bone formation may cause metabolic disorders

\footnotetext{
* Correspondence: sahabjada@erauniversity.in;

sahabjadabiotech04@gmail.com; arshadm123@rediffmail.com

'Department of Biotechnology, Era's Lucknow Medical College \& Hospital, Era University, Lucknow 226003, India

2Department of Zoology, University of Lucknow, Lucknow 226007, India Full list of author information is available at the end of the article
}

or bone pathological conditions of the adult skeleton and lead to low bone mass, osteoporosis, and increased bone fracture risk [2]. Based on available data and clinical experiences, about 200 million women worldwide are osteoporotic and report approximately 8.9 million fractures annually [3]. This is equivalent to an osteoporotic fracture every $3 \mathrm{~s}$ in the woman [4]. The most common risk factors for osteoporotic fracture are deteriorating bone mineral density along with advanced age [5]. Therefore, diet strategies, including functional

C C The Author(s). 2020 Open Access This article is licensed under a Creative Commons Attribution 4.0 International License, which permits use, sharing, adaptation, distribution and reproduction in any medium or format, as long as you give appropriate credit to the original author(s) and the source, provide a link to the Creative Commons licence, and indicate if changes were made. The images or other third party material in this article are included in the article's Creative Commons licence, unless indicated otherwise in a credit line to the material. If material is not included in the article's Creative Commons licence and your intended use is not permitted by statutory regulation or exceeds the permitted use, you will need to obtain permission directly from the copyright holder. To view a copy of this licence, visit http://creativecommons.org/licenses/by/4.0/ The Creative Commons Public Domain Dedication waiver (http://creativecommons.org/publicdomain/zero/1.0/) applies to the data made available in this article, unless otherwise stated in a credit line to the data. 
foods and nutraceuticals, can be valuable assets for the peak bone mass of an individual and can support bone health during later life stages. Thus, with a rise in the life expectancy of people, the need for prevention and bone preservation measurements is greater than ever.

For osteoporosis treatments, most pharmaceuticals concentrate on inhibition of osteoclastogenesis to retard bone resorption, while preventive strategies are most important. Previous studies have shown that isoflavones and flavonoids increase bone mass density and prevent bone loss in-vivo and in-vitro [6-8]. Thus, flavonoids and isoflavones have the potential to maintain and improve the bone mass of human subjects. Flavonoids and isoflavones are secondary metabolites found in various plant parts such as fruits, vegetables, grains, flowers, roots, barks and stems [9]. Genistein (4',5,7-trihydroxyisoflavone, GS) structurally belongs to the group of isoflavones which have potential to be developed into antiosteoporotic and anticancer drugs. GS is present in various food items primarily in soybeans and soy products, which is capable of interacting with various hormones like estrogens $[10,11]$.

Several studies have reported the osteogenic activity of various herbal compounds on the primary culture of rodent bone cells which is an easy available model to study the fundamental processes involved in bone formation and relevant for clinical studies. Icariin, a prenylated flavonol glycoside, has been reported to have potential for bone cell formation using rat calvarial osteoblast culture [12]. Likewise, a Chinese medicinal plant, Alpinia officinarumHance., has shown osteogenic activity in both ovariectomized Sprague Dawley (SD) rats as well as in primary osteoblasts and has a protective role against the lethal effects of intracellular ROS generation [13]. Mice calvaria osteoblasts have been tested in vitro for osteoblast mineralization using water extract of Rumex crispus root [14]. In addition, ethanolic extract of Punica granatum and methanolic extracts of mistletoe leaves and their isolated compounds have shown osteogenic potential in primary rat calvaria culture $[15,16]$. Genistein has also been reported to prevent trabecular bone loss of proximal tibia in a male rat model of osteoporosis [17] and in combination with silicon, it also protects ovariectomized bone loss by upregulating OPG/RANKL ratio [18]. In addition, previous studies have reported that genistein inhibits lipopolysaccharide-stimulated inflammatory and oxidative stress response as well as RANKL-stimulated osteoclast differentiation using RAW 264.7 macrophage cell lines $[19,20]$. However, further studies are needed to justify the role of GS in regulation of cell cycle and oxidative stress in primary culture of bone cells along with osteoclasts attenuation in bone marrow progenitor cells.

In this study, cultured bone cells were exposed to different concentrations of GS and the effect of GS on cell cycle progression and oxidative stress along with osteogenic gene expression were analyzed in primary osteoblasts. Inhibition of osteoclasts differentiation by GS was analyzed in bone marrow-derived osteoclast cells. Our findings indicated that GS has beneficial effects on bone regeneration and preservation.

\section{Methods}

\section{Reagents and chemicals}

Alpha- minimum essential medium (a-MEM), foetal bovine serum (FBS), MTT powder, $\mathrm{p}$-nitrophenyl phosphate (pNPP), naphthol AS-MX phosphate, fast blue BB salt, ascorbic acid and Alizarin Red $S$ dye were purchased from Himedia, India. Propidium iodide (PI), $\beta$ glycerophosphate, 2,7-dichlorodihydrofluorescein diacetate (DCFH-DA) and 17 $\beta$-estradiol (E2) were purchased from Sigma-Aldrich, USA. RNAiso Plus reagent was procured from Takara, India. Revert Aid First Strand cDNA Synthesis Kit was procured from Thermo Scientific, USA and LightCycler ${ }^{\circ} 480$ SYBR Green I kit was purchased from Roche, Germany. Anti-BMP2 antibody and anti-cathepsin $\mathrm{K}$ antibody were procured from Molecular Probes, USA. All other chemicals were of analytical grade.

\section{Culture and maintenance of osteoblasts}

For isolation and culrture of bone cells, SD rats were obtained from Central Drug Research Institute, Lucknow, India and the protocols employed were ethically approved by Institutional Animal Ethics Committee of Azad Institute of Pharmacy and Research, Lucknow, India (Ref No. AIPR/2013-14/ 1398).

Osteoblasts were isolated from the calvaria of rat pups by sequential digestion as per established protocols [16]. Briefly, 2-3 days old neonatal rat pups in number 6-8 were cervical dislocated by applying firm pressure at the base of skull, sharply pinching and twisting between thumb and forefinger and at the same time, pulling backward on the tail. Calvaria was excised with the help of scissors, scalpels, and forceps. Isolated calvaria was subjected to five successive digestions in a solution containing $0.1 \%$ collagenase II and dispase II enzymes at $120 \mathrm{rpm}$ and $37^{\circ} \mathrm{C}$ for $10-15 \mathrm{~min}$ in a shaking water bath. Supernatants from second to fifth digestions were collected in a $15 \mathrm{ml}$ tube containing $800 \mu \mathrm{l} \mathrm{FBS}$ and then centrifuged. Pellets were resuspended in complete $\alpha$ MEM media and cultured in $\mathrm{T}^{-25} \mathrm{~cm}^{2}$ flasks at $37{ }^{\circ} \mathrm{C}$ with $5 \% \mathrm{CO}_{2}$ in a $\mathrm{CO}_{2}$ incubator (Excella ECO-170, New Brunswick).

\section{Isolation and culture of bone marrow progenitor cells}

For osteoclast culture, bone marrow progenitor cells from femur and tibia bones of rodents were isolated as 
per described protocol with minor modifications [21]. Briefly, 4-6 days neonatal rat pups were cervical dislocated as mentioned previously. Long bones of neonatal rats were isolated and cleared the soft tissues using sterile surgical blades. Bones were washed with ice-cold PBS, cut lengthwise and then chopped finely using a scalpel blade in a petri-dish containing $\alpha$-MEM without FBS. The cell suspensions containing bone marrow were collected in a tube and centrifuged at $1500 \mathrm{rpm}$ for 5 $\mathrm{min}$. Settled cells were cultured in $\alpha$-MEM containing heat-inactivated FBS and M-CSF $(30 \mathrm{ng} / \mathrm{ml})$ at $37^{\circ} \mathrm{C}$ and $5 \% \mathrm{CO}_{2}$. After $24 \mathrm{~h}$ incubation, overlaying medium was discarded and settled cells were pooled in a tube by gentle washing with sterile PBS. The cell suspension was centrifuged at $1500 \mathrm{rpm}$ for $5 \mathrm{~min}$ and pellet was recultured in osteoclast differentiating media (osteoclast media containing $10 \% \mathrm{FBS}$, antibiotics solution, $10^{-8} \mathrm{M}$ vitamin $\mathrm{D}_{3}$ and $10^{-6} \mathrm{M}$ dexamethasone + M-CSF $30 \mathrm{ng} /$ $\mathrm{ml}+\mathrm{RANKL} 50 \mathrm{ng} / \mathrm{ml})$.

\section{Osteoclastogenesis and treatment}

Fresh osteoclast differentiating media containing desired concentrations (1, 5 and $10 \mu \mathrm{M})$ of GS was used to replace old media of cultured osteoclasts in a 24-well plate at every 3 days. After 9 days of treatment, cells were used for TRAP staining, Cathepsin $\mathrm{K}$ gene expression analysis and their immunofluorescence staining. Multinucleated cells containing $\geq 3$ nuclei were scored as TRAP-positive osteoclast cells.

\section{Cell proliferation analysis}

The proliferative effect of GS was determined by MTT assay as per protocol [22]. Briefly, cultured osteoblasts at a density of $2 \times 10^{3}$ cells/well were seeded in 96-well plate and incubated with GS solution prepared in culture media at concentrations 1,5 and $10 \mu \mathrm{M}$ in triplicate for $48 \mathrm{~h}$. The $17 \beta$-estradiol (E2) at $1 \mathrm{nM}$ was considered as a positive control because it can produce maximum induction in osteoblasts as per organisation for economic cooperation and development (OECD) guidelines. MTT reagent was added and the colored product was read at $540 \mathrm{~nm}$ using a microplate reader (BIORAD-680, USA). Cells growth was analyzed by using the equation:

$$
\% \text { Cells Growth }=\frac{\text { Absobance of treated cells }}{\text { Absobance of control cells }} \times 100
$$

\section{ALP activity of osteoblasts}

ALP activity of osteoblasts was evaluated using the following protocol [15]. Briefly, osteoblasts at density $2 \times$ $10^{3}$ cells/well were seeded in a 96-well plate using osteoblast differentiation medium containing complete $\alpha$ MEM supplemented with $10 \mathrm{mM} \quad \beta$-glycerophosphate and $50 \mu \mathrm{g} / \mathrm{ml}$ ascorbic acid. After overnight, cells were incubated with GS at concentrations 1,5 and $10 \mu \mathrm{M}$ for $48 \mathrm{~h}$. Treated and untreated cells were fixed in $4 \%$ paraformaldehyde and then stained with ALP reagent (naphthol ASMX phosphate at $0.1 \mathrm{mg} / \mathrm{ml}, \mathrm{N}, \quad \mathrm{N}$ dimethylformamide at $0.5 \%, \mathrm{MgCl}_{2}$ at $2 \mathrm{mM}$, and fast blue $\mathrm{BB}$ salt at $0.6 \mathrm{mg} / \mathrm{ml}$ in Tris- $\mathrm{HCl}$ solution of 0.1 $\mathrm{mM}$ and $\mathrm{pH} 8.5)$ for $30 \mathrm{~min}$. Images were captured under an inverted phase-contrast microscope (Nikon ECLIPSE Ti-S, Japan). To quantify the stain, the plate was placed at $-70^{\circ} \mathrm{C}$ for $20 \mathrm{~min}$, and then freeze fractured at $37^{\circ} \mathrm{C}$. The chilled pNPP substrate solution was added and incubated further at $37^{\circ} \mathrm{C}$ for color development. Absorbance was read at $405 \mathrm{nM}$ with the help of ELISA reader.

\section{Calcium deposition assay}

Calcium content in osteoblasts was measured using Alizarin Red S dye after 3 weeks of treatment periods following a previous protocol [15]. Approximately, osteoblasts at a density $2 \times 10^{4}$ cells/well were cultured in osteoblast differentiation medium containing $10^{-7} \mathrm{M}$ dexamethasone in a 12-well culture plate. Cells were incubated with and without GS at desired concentrations for 21 days at $37^{\circ} \mathrm{C}$ in a $\mathrm{CO}_{2}$ incubator. The medium was replaced every $48 \mathrm{~h}$ with fresh treatment for 21 days. Cells were then fixed with $4 \%$ paraformaldehyde for 15 min and then rinsed twice with PBS followed by Alizarin Red-S staining ( $40 \mathrm{mM}, \mathrm{pH} 4.5)$ for $30 \mathrm{~min}$. Stained calcified nodules were photographed using inverted phasecontrast microscopy. Alizarin stain was extracted with $100 \mathrm{mM}$ cetylpyridinium chloride solution and released calcium-bound alizarin red solution was used for colorimetric quantification at $570 \mathrm{~nm}$ using a microplate reader (BIORAD-680, USA).

\section{DNA content analysis in S-phase of the cell cycle}

DNA content analysis in S-phase of cells population by flow cytometry is the method of cell proliferation. For this study, primary osteoblast cells were seeded at density $1 \times 10^{6}$ cells $/ \mathrm{ml}$ in 6 -well culture plates and then treated with GS at desired concentrations for $48 \mathrm{~h}$. Flow cytometry study was carried out to analyze the cellular DNA content using standard protocol [15]. The fluorescence intensity of stained nuclei was measured with the help of flow cytometer (BD FACS Calibur, Becton Dickinson, USA) and data were analyzed.

\section{Measurement of the antioxidant ability of GS}

Hydrogen peroxide $\left(\mathrm{H}_{2} \mathrm{O}_{2}\right)$ solvent was used as an exogenous ROS source inducing oxidative stress and free radicals in osteoblasts. The osteoblast cells were incubated with various concentrations of $\mathrm{H}_{2} \mathrm{O}_{2}(10-100 \mu \mathrm{M})$ for $24 \mathrm{~h}$ and the $\mathrm{IC}_{50}$ value was evaluated as described 
previously [22]. Further, to investigate the antioxidant ability of GS on osteoblasts, the confluent cells were pre-treated with 1,5 and $10 \mu \mathrm{M}$ concentrations of GS for $24 \mathrm{~h}$ and then treated with or without Sub- $\mathrm{IC}_{50}$ value $(40 \mu \mathrm{M})$ of $\mathrm{H}_{2} \mathrm{O}_{2}$ for $24 \mathrm{~h}$. After incubation period, cells were stained with DCFH-DA dye for $20 \mathrm{~min}$ and imaged from 5 to 7 random fields of each sample under an inverted fluorescence microscope (Nikon ECLIPSE Ti-S, Japan). For ROS quantification, osteoblasts were incubated with DCFH-DA dye in PBS and the fluorescence was quantified at excitation wavelength $485 \mathrm{~nm}$ and emission wavelength $528 \mathrm{~nm}$ by a multiwell microplate reader (Synergy H1 Hybrid Multi-Mode Microplate Reader, BioTek, USA).

\section{Real-time quantitative PCR (qPCR) analysis}

Both osteoblasts and osteoclast cells were treated with different concentrations of GS and gene expression analysis was performed following a previous protocol [23]. Briefly, total RNA was isolated from cultured osteoblasts using RNAiso Plus reagent (Takara, India) following the manufacturer's instructions. A $1 \mu \mathrm{g}$ of isolated RNA was used in $20 \mu \mathrm{l}$ reaction volume and cDNA was synthesized using Revert Aid First Strand cDNA Synthesis Kit (Thermo Scientific, USA). Concentrations of cDNA were measured by spectrophotometer and $12.5 \mathrm{ng} / \mu \mathrm{l} \mathrm{cDNA}$ was used for qPCR reaction. For absolute quantification of both osteogenic and osteoclastic gene expression, real-time PCR analysis was performed in a light cycler PCR system (Light Cycler 480, Roche, Germany) using LightCycler ${ }^{\circ} 480$ SYBR Green I kit (Roche, Germany). For absolute quantification, a standard curve was prepared from treated and untreated cells of known template concentration and the concentration of the unknown sample was determined by interpolation of its PCR signal (cycle threshold) into the standard curve. The sequence of primer pairs is listed in Table S1.

\section{Immunofluorescence staining of BMP2 protein}

Immunofluorescence staining was performed as per the previous protocol [23]. Treated and untreated cells were fixed in $4 \%$ paraformaldehyde and permeabilized with permeabilizing buffer. Cells were washed with PBS and then blocked with blocking buffer at RT for $1 \mathrm{~h}$ to avoid non-specific binding. Cells were then incubated with a rat anti-BMP2 antibody (1:1000 dilution, Abcam, Cambridge, UK) containing $0.5 \% \mathrm{BSA}$ at $4{ }^{\circ} \mathrm{C}$ for overnight. After washing with PBS, cells were incubated with fluorescent Alexa Fluor-488 conjugated anti-rat BMP2 antibody (1:1000 dilution, Molecular Probes, USA) for $1 \mathrm{~h}$ at RT. Cells were washed with PBS and then photographed under a fluorescent microscope (Nikon ECLIPSE Ti-S, Japan). BMP2-stained cells were counted in five randomly selected fields from three wells of each treatment

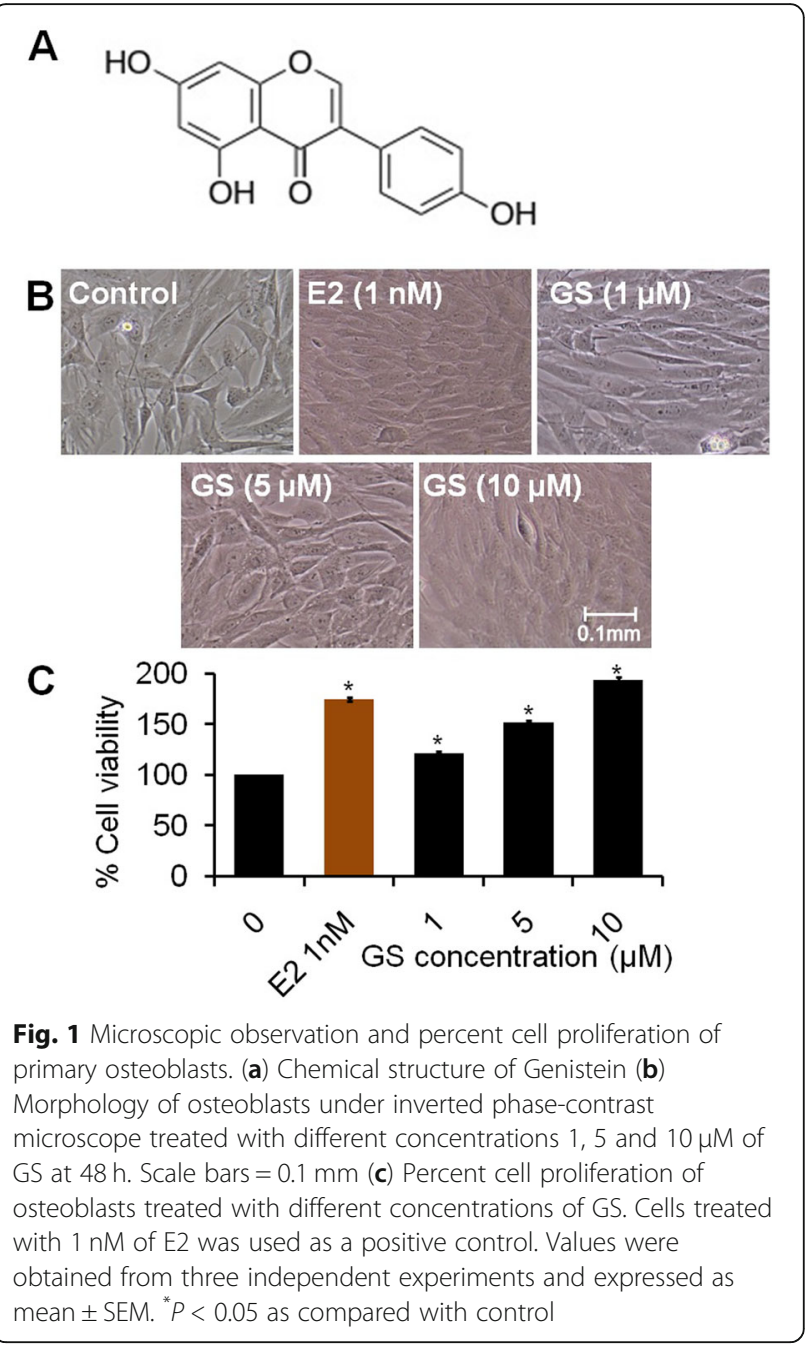

and analyzed with Image-Pro Plus 6.1 software (Media Cybernetics, Rockville, MD, USA).

\section{TRAP staining assay}

TRAP staining was performed as per the described protocol [24]. Briefly, cultured cells in a 24-well plate were fixed with fresh $4 \%$ paraformaldehyde for $10 \mathrm{~min}$. Subsequently, $0.5 \mathrm{ml}$ of staining reagent $(5-10 \mathrm{mg}$ Naphthol AS-MX phosphate in $0.5 \mathrm{ml}$ dimethylformamide $+50 \mathrm{ml}$ acetatetartrate buffer $+20 \mathrm{mg}$ fast red violet LB salt) was added in each well and incubated at RT for 5-10 min. Cells were washed twice with distilled water and photographs were taken by an inverted phase-contrast microscope.

\section{Immunofluorescence staining of Cathepsin $\mathrm{K}$}

Cathepsin $\mathrm{K}$ activity was assayed qualitatively by cathepsin $\mathrm{K}$ immunofluorescence staining following protocol with little modification [25]. Cells were fixed in $4 \%$ paraformaldehyde, permeabilized with permeabilization buffer, and then blocked with blocking buffer at RT for $1 \mathrm{~h}$. 
Next, cells were incubated with rat anti-cathepsin K antibody (1:1000 dilution, Abcam, Cambridge, UK) containing $0.5 \% \mathrm{BSA}$ at $4{ }^{\circ} \mathrm{C}$ for overnight. After the incubation period, cells were then washed with $\mathrm{PBS}$ and incubated with fluorescent Alexa Fluor-488 conjugated anti-rat cathepsin $\mathrm{K}$ antibody (1:1000 dilution in PBS) (Molecular Probes, USA) for $1 \mathrm{~h}$ at RT. Stained cells were photographed using a fluorescent microscope (Nikon ECLIPSE Ti-S, Japan). Cathepsin K- stained cells were counted in five randomly selected fields from three wells of each treatment and analyzed using Image-Pro Plus 6.1 software.

\section{Statistical analysis}

All triplicates data were represented as means \pm SEM. One-way ANOVA and Dunnett's multiple comparison tests were implemented for statistical significance. Student $\mathrm{t}$-test was also applied as per experimental need using Microsoft Excel and Roche software. A probability value of $\mathrm{P}<0.05$ was considered statistically significant.

\section{Results}

\section{Effect of GS on osteoblasts growth}

The elongated and fusiform appearance of osteoblasts was observed under an inverted phase-contrast microscope. Compact and dense layering of cells at high doses revealed growth of osteoblast cells (Fig. 1b). Figure 1a represents the chemical structure of genistein. Data of MTT assay revealed that 1,5 and $10 \mu \mathrm{M}$ concentrations of GS resulted in approximately 121.66, 151.50, and 193.23\% growth as compared to control. Exposure of cells with $1 \mathrm{nM}$ of E2 (positive control) increased the growth of cells to $174.84 \%$ as compared to control (Fig. 1c). MTT data was consistent with the morphological data of osteoblasts.

\section{Effect of GS on ALP activity}

ALP is an early differentiation marker of osteoblasts and the amplified expression of ALP is highly correlated with the progressive differentiation of osteoblasts. Data of ALP stain showed that GS increased the ALP stain upon increasing the concentrations of GS (Fig. 2a). The quantitative data of ALP is represented in the form of absorbance at different concentrations of GS treatment. As observed from the results (Fig. 2b), GS induced cell differentiation significantly $(P<0.05)$ depending upon dose. Cells exposed with $1 \mathrm{nM}$ of E2 also increased the ALP activity as compared to control.

\section{GS induces mineralization of osteoblasts}

As revealed by results, osteoblasts displayed monolayer fibroblastic appearance in the proliferation period in control cells. Cells treated with various concentrations of GS appeared to form mosaic-like multiple layers at 1, 5 and $10 \mu \mathrm{M}$ of doses (Fig. 2c). After 21 days, the quantitative calcification data of osteoblasts at different concentrations of GS is shown in Fig. 2d. As observed from the data, GS increased the calcified nodules formation in cultured osteoblasts, which exhibits significant osteogenic effect $(P<0.05)$ as a function of dose.

\section{DNA content analysis}

As observed from the result, the normal distribution of different phases of the cell cycle was found in the
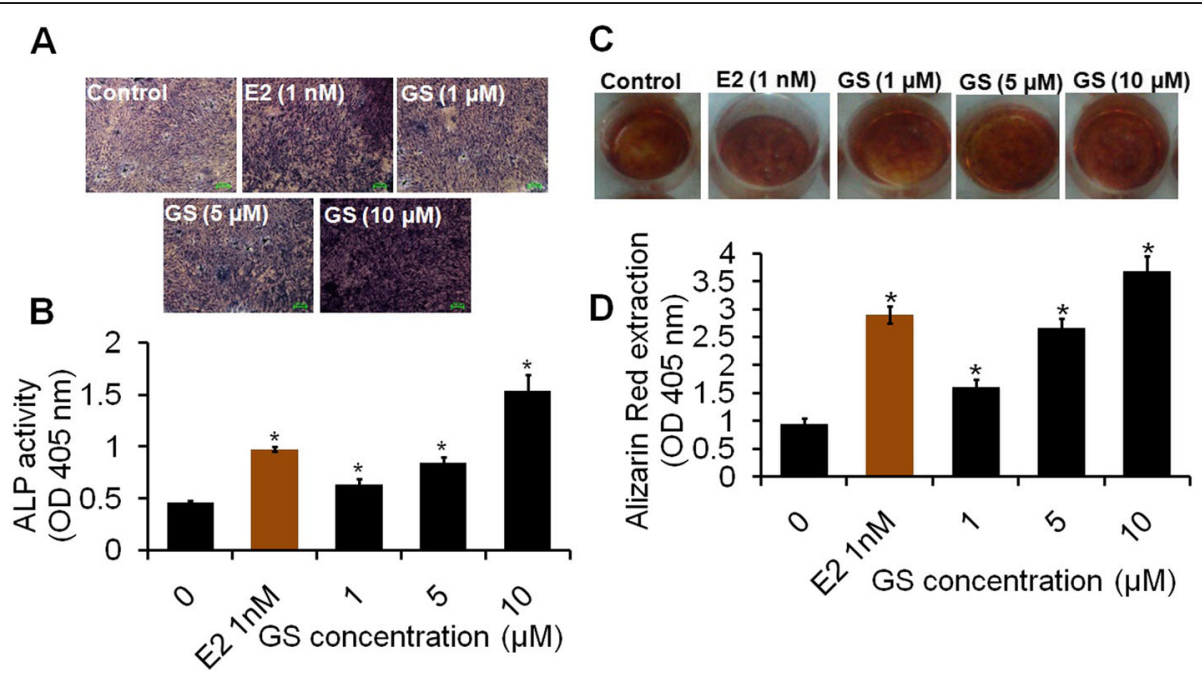

Fig. 2 Effect of GS on osteoblasts differentiation and calcification (a) Photomicrographs show ALP stain in osteoblasts treated with increasing concentrations 1, 5 and $10 \mu \mathrm{M}$ of GS at $48 \mathrm{~h}$ (b) Quantitative data of ALP level are presented in the form of ALP activity relative to control (c) Photomicrographs represent the increased formation of mineralized nodules of osteoblasts treated with increasing concentrations 1,5 and $10 \mu \mathrm{M}$ of GS at 21 days. Scale bars $=0.1 \mathrm{~mm}$ (d) Quantitative data of Alizarin Red-S extraction are expressed in the form of percent calcification. Data are represented as mean \pm SEM of three independent experiments. ${ }^{*} P<0.05$ as compared with control 
control group. As compared to control, \% DNA content in S phase of cell cycle was sharply increased from 11.76 to $16.66 \%$ at $1 \mu \mathrm{M}$ of GS treatment. A notable increase in the percent DNA content of S phase was observed by 41.79 and $52.23 \%$ at 5 and $10 \mu \mathrm{M}$ of GS treatment (Fig. 3). Exposure of $1 \mathrm{nM} \mathrm{E2}$ compound to osteoblasts increased the \% DNA content in S phase by $48.55 \%$.

\section{GS reduced the oxidative stress of osteoblasts}

To evaluate the antioxidant effect of GS, $\mathrm{H}_{2} \mathrm{O}_{2}$ was employed as an exogenous ROS source to induce oxidative stress in osteoblasts. $\mathrm{H}_{2} \mathrm{O}_{2}$ treatment reduced the number of cells considerably as compared to untreated cells (Fig. 4a). MTT data showed that $\mathrm{H}_{2} \mathrm{O}_{2}$ decreased the percent viability of osteoblasts depending upon dose (Fig. 4b). The cell viability data of osteoblasts was consistent with decreasing number of treated osteoblasts. The $\mathrm{IC}_{50}$ value of $\mathrm{H}_{2} \mathrm{O}_{2}$ was found $45.8 \mu \mathrm{M}$ against osteoblasts. Therefore, a sub- $\mathrm{IC}_{50}$ value of $\mathrm{H}_{2} \mathrm{O}_{2}$ i.e. $40 \mu \mathrm{M}$ was used to induce osteoblasts oxidative stress in later experiments. Pre-treated osteoblasts with GS at 1, 5 and $10 \mu \mathrm{M}$ concentrations for $24 \mathrm{~h}$ followed by $40 \mu \mathrm{M} \mathrm{H}_{2} \mathrm{O}_{2}$ incubation for another $24 \mathrm{~h}$, GS significantly attenuated the $\mathrm{H}_{2} \mathrm{O}_{2}$-induced injury depending upon dose. These results suggests that GS may suppress $\mathrm{H}_{2} \mathrm{O}_{2}$-induced cell death. As shown in Fig. 4c, after $24 \mathrm{~h}$ of $\mathrm{H}_{2} \mathrm{O}_{2}$ incubation, the DCFHDA fluorescence intensity of osteoblasts was increased significantly as compared to control. This result suggests that enhanced intracellular ROS level of osteoblasts may result into damage of their cellular function. On the other hand, ROS generation was significantly inhibited by GS at its each concentrations of treatment. Reference control E2 at $1 \mathrm{nM}$ concentration reduced the ROS level as compared to control.

\section{qPCR analysis of osteogenic genes expression}

Osteogenic genes expression of bone cells treated with various concentrations of GS were observed by absolute $\mathrm{qPCR}$ at $48 \mathrm{~h}$. As observed from the result, 1, 5 and $10 \mu \mathrm{M}$ of GS elevated Runx 2 expression significantly $(P<0.05)$ as compared to control (Fig. 5a). On the other hand, the mRNA level was found greater at $10 \mu \mathrm{M}$ of GS treatment as compared to E2 treatment. Figure 5b shows that GS induces the expression of BMP2 significantly $(P<0.05)$ depending upon dose as compared to control. However, BMP2 expression at $10 \mu \mathrm{M}$ of GS treatment was found to be greater as compared to $1 \mathrm{nM}$ E2. This study also suggests that the osteogenic effect of GS may be mediated through increased production of BMP2. Furthermore, the downstream gene expression of Runx2

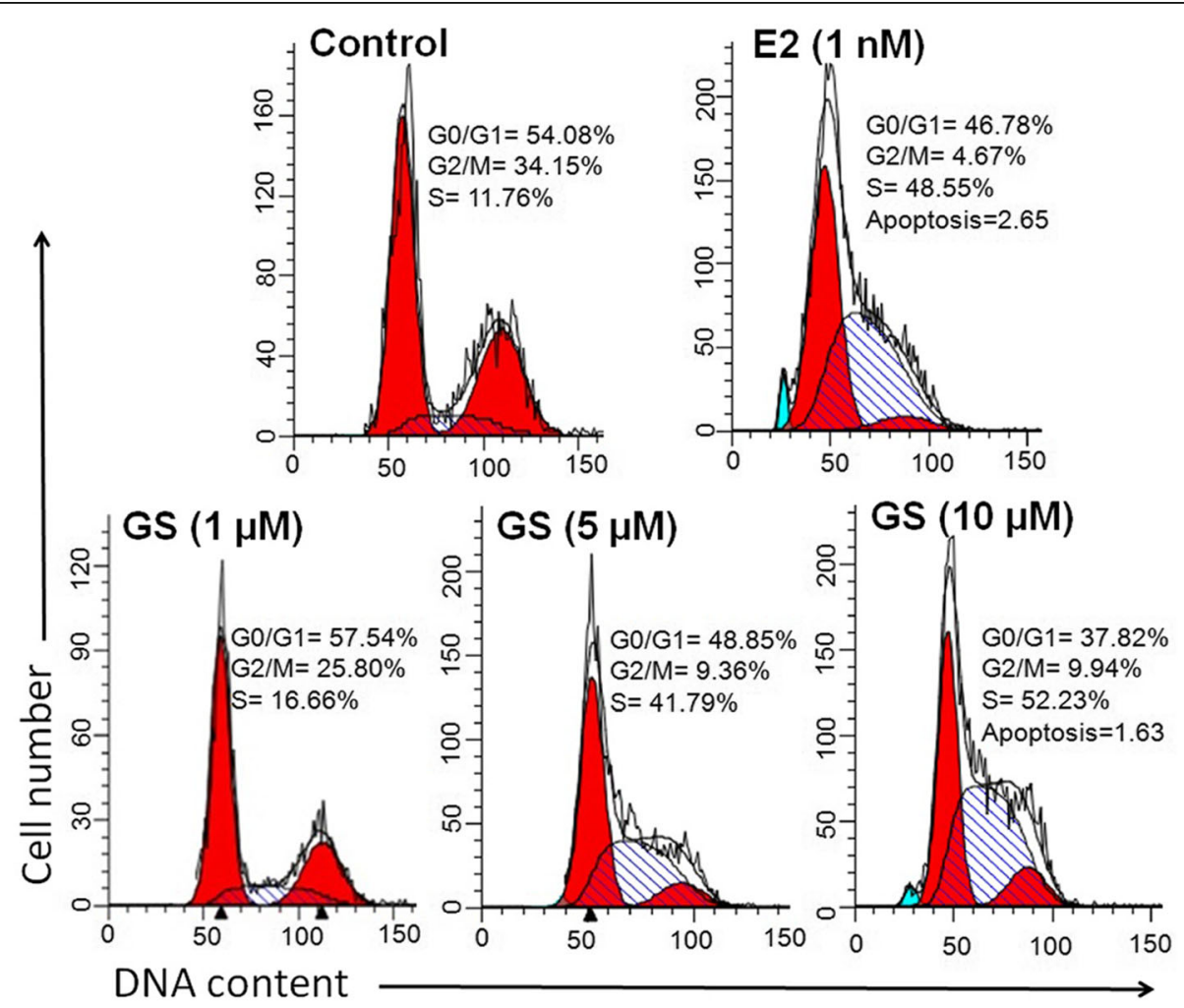

Fig. 3 Analysis of cell cycle progression by flow cytometry. Pictorial graph showing the proportion of cells in different phases of cell cycle treated with 1, 5, and $10 \mu \mathrm{M}$ of GS at $48 \mathrm{~h}$. Cells treated with $1 \mathrm{nM}$ of E2 was used as a positive control 

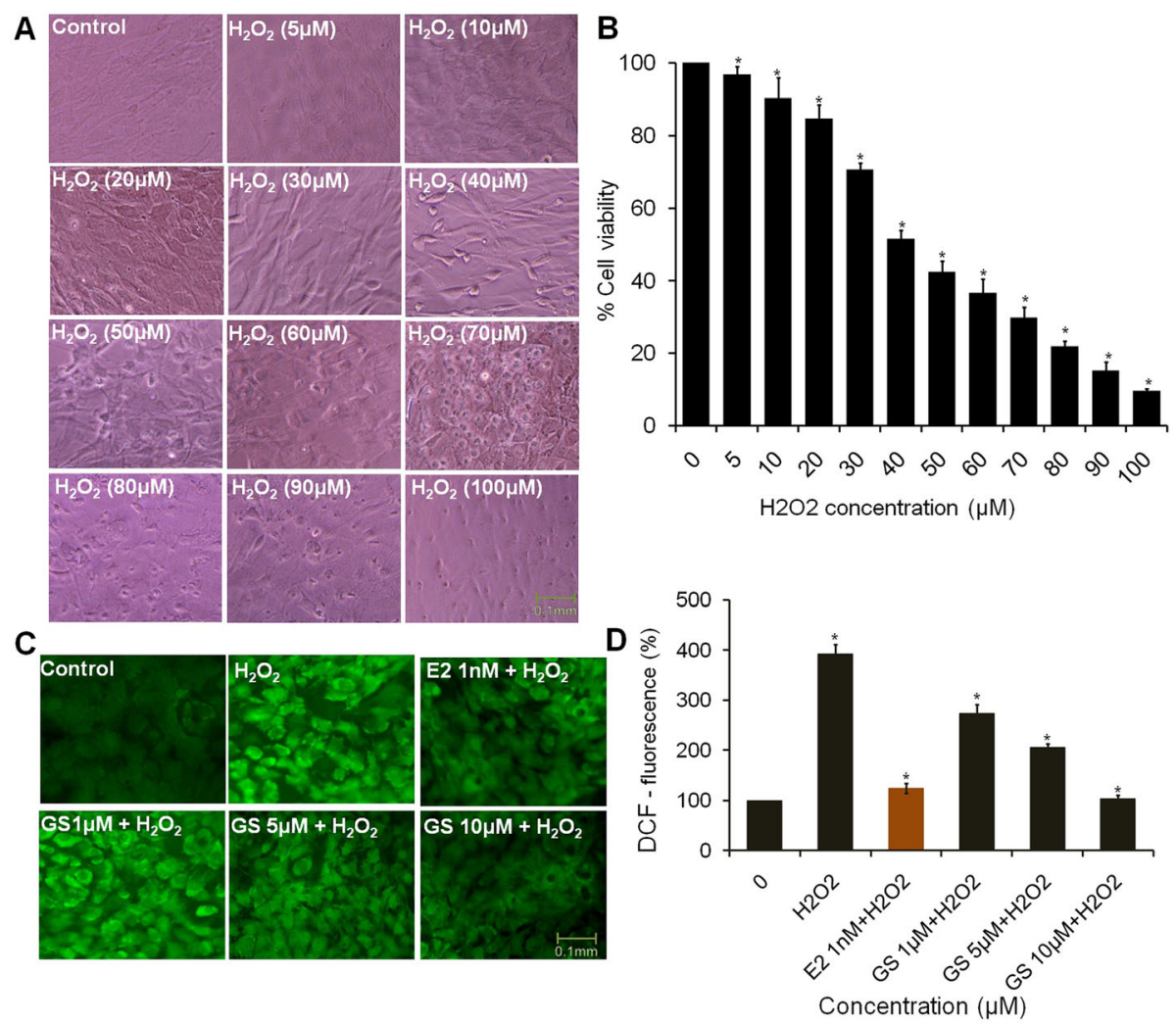

Fig. 4 Protective effect of GS on $\mathrm{H}_{2} \mathrm{O}_{2}$-induced cytotoxicity and intracellular oxidative status in osteoblasts. a Concentration-dependent effects of $\mathrm{H}_{2} \mathrm{O}_{2}$ exposure on the morphology of osteoblasts after $24 \mathrm{~h}$ (b) Concentration-dependent effects of $\mathrm{H}_{2} \mathrm{O}_{2}$ exposure on viability of osteoblasts (c) Representative photomicrographs show intracellular ROS generation stained with DCFH-DA dye, Scale bar $=100 \mu$ m (d) Quantitative

measurement of ROS level of osteoblasts was expressed as the percentage of DCF-fluorescence relative to controls. Values were obtained from three independent experiments and expressed as mean \pm SEM. ${ }^{*} P<0.05$ compared with control

i.e. osteocalcin was also increased considerably in treatment groups compared to controls (Fig. 5c).

\section{Immunofluorescence staining of BMP2}

The result of BMP2 immunofluorescence stain clearly indicated that GS elevated BMP2 level as a function of dose (Fig. 5d). This data is also compatible with qPCR data of BMP2 expression.

\section{Effect of GS on osteoclastogenesis}

TRAP staining of osteoclasts exhibited that GS decreased the osteoclastogenesis by reducing the differentiation of multinucleated osteoclasts (Fig. 6a). As observed from quantitative results, GS reduced TRAP+ multinucleated cells number significantly depending upon dose when compared to control (Fig. 6b).

\section{Cathepsin $\mathrm{K}$ expression analysis}

Osteoclast is characterized by the expression of cathepsin $\mathrm{K}$ which is a cysteine protease working as a potent collagenase. Results of expression analysis of cathepsin $\mathrm{K}$ indicated that GS decreased the cathepsin $\mathrm{K}$ expression dose-dependently compared to control (Fig. 6c). Although, $10 \mu \mathrm{M}$ dose of GS reduced the level of cathepsin $\mathrm{K}$ significantly compared to E2 treatment. This data was consistent with result of TRAP stain. Furthermore, result of immunofluorescence stain of cathepsin $\mathrm{K}$ indicated that GS decreased the extent of cathepsin K stain dosedependently compared to control (Fig. 6d). This result indicates that the flavonoid nature of GS may be responsible for the reduction of cathepsin $\mathrm{K}$ expression which may thus slow the degenerative changes of bone.

\section{Discussion}

Bone remodeling is a tightly regulated process that is characterized by bone resorption by osteoclasts and bone formation by osteoblasts. Disruption of this finely regulated process leads to osteoporosis. Therefore, induction of bone formation and reduction of bone resorption would be the leading steps in osteoporosis therapy. In the present study, soy isoflavone genistein was used to its effect(s) on osteoblast proliferation and differentiation, oxidative stress and cell cycle progression in primary osteoblasts, as well as osteoclast attenuation. 


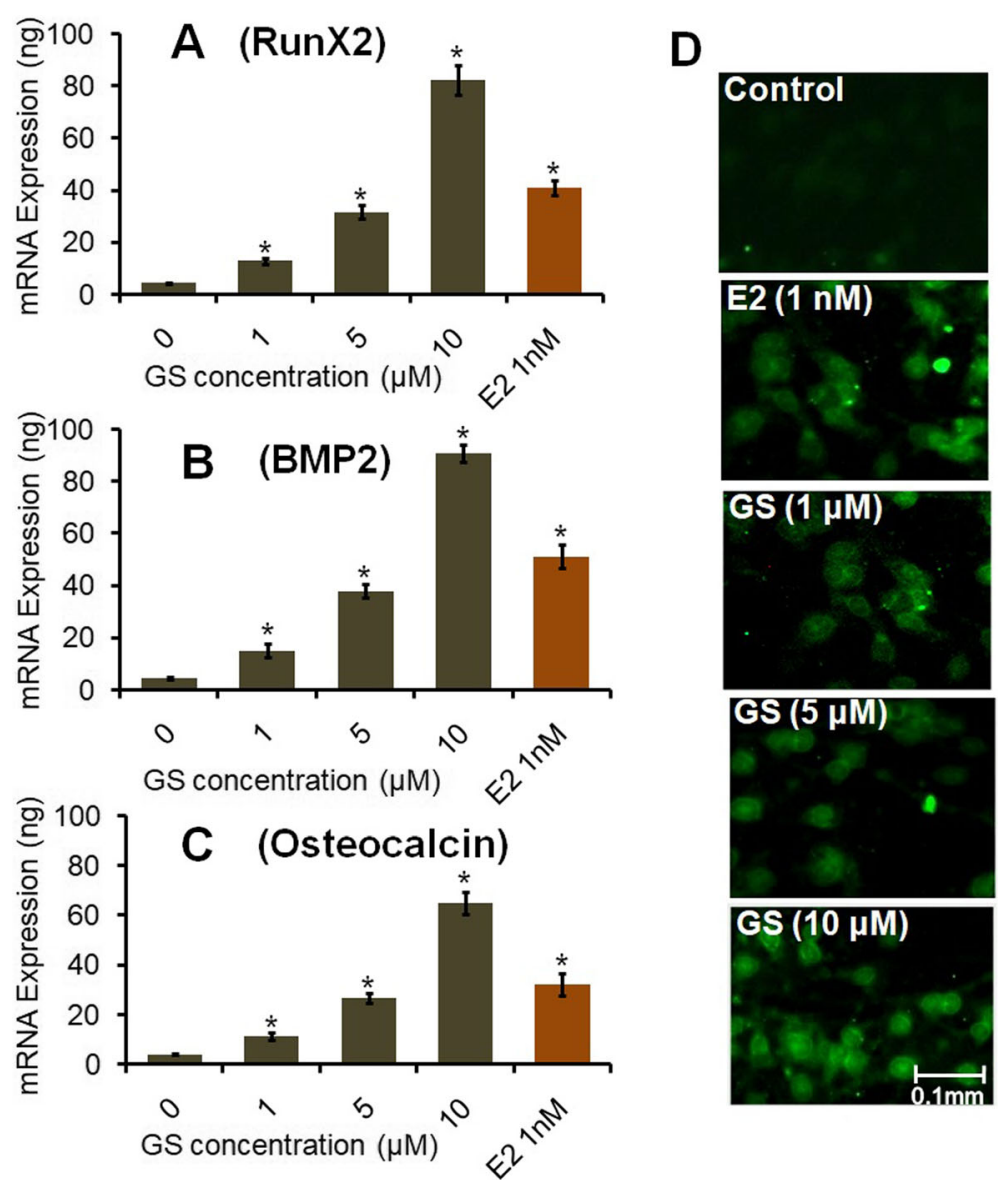

Fig. 5 Effect of GS on mRNA levels of osteogenic genes and immunolocalization of the BMP2 protein in osteoblasts. Rat calvarial osteoblasts were treated with different concentrations 1, 5 and $10 \mu \mathrm{M}$ of GS for $48 \mathrm{~h}$. Absolute qPCR was performed to analyze the mRNA expressions of (a) Runx2 (b) BMP2 and (c) Osteocalcin genes in osteoblasts. $\mathbf{d}$ Photomicrographs show the immunofluorescence staining of BMP2 under inverted fluorescence microscope; magnification $=20 \mathrm{x}$ and scale $\mathrm{bar}=0.1 \mathrm{~mm}$. Values were obtained from three independent experiments performed in the triplicate set and expressed as mean \pm SEM; ${ }^{*} P<0.05$

Cell viability data revealed that GS treatment increased the growth of osteoblasts by increasing the growth and amount of live cells (Fig. 1a \& b). The elongated and fusiform morphology of osteoblasts suggested the features of bone cell proliferation. This result is consistent with some previous reports where GS induced cell proliferation in primary mouse bone marrow-derived mesenchymal stem cells and human osteoblast cell line hFOB 1.19 $[26,27]$. Alkaline phosphatase enzyme plays an essential role in the mineralization of osteoblasts and, thus, matrix mineralization is the vital process in bone formation. A previous study has investigated the combined effect of flavonoids daidzein and genistein increasing alkaline phosphatase activity in cultured MC3T3-E1 preosteoblastic cells [28]. This study is in agreement with the result of ALP activity of the present study and thus, suggests that GS has a stimulatory effect on osteoblasts differentiation. The mineralization promoting potential of GS observed in the present study has been found to be in agreement with another study which has reported that the dietary flavone baicalin causes a strong induction of alkaline phosphatase and increases mineralization in cultured rat osteoblasts [29].

Measurement of percent of cells in S phase or S-phase fraction determines whether cells are in a proliferative phase of cell cycle or not [30]. Cell cycle data displayed that GS caused accumulation of cells in $S$ phase of cell cycle. Accumulation in $\mathrm{S}$ phase of cell cycle may have two meaning; either the cells grow or they are arrested because of DNA damage in apoptosis. Interestingly, the present data suggest that GS induces cell proliferation by accumulating the cells in $\mathrm{S}$ phase of cell cycle. These findings has been validated by other studies by examining induction of estrogen receptor expression and chondrocyte proliferation in S phase of the cell cycle [31, 32]. A recent study has reported that a biologically proliferative dose of Cibotium barometz polysaccharides stimulates in vitro chondrocyte proliferation via increasing the 

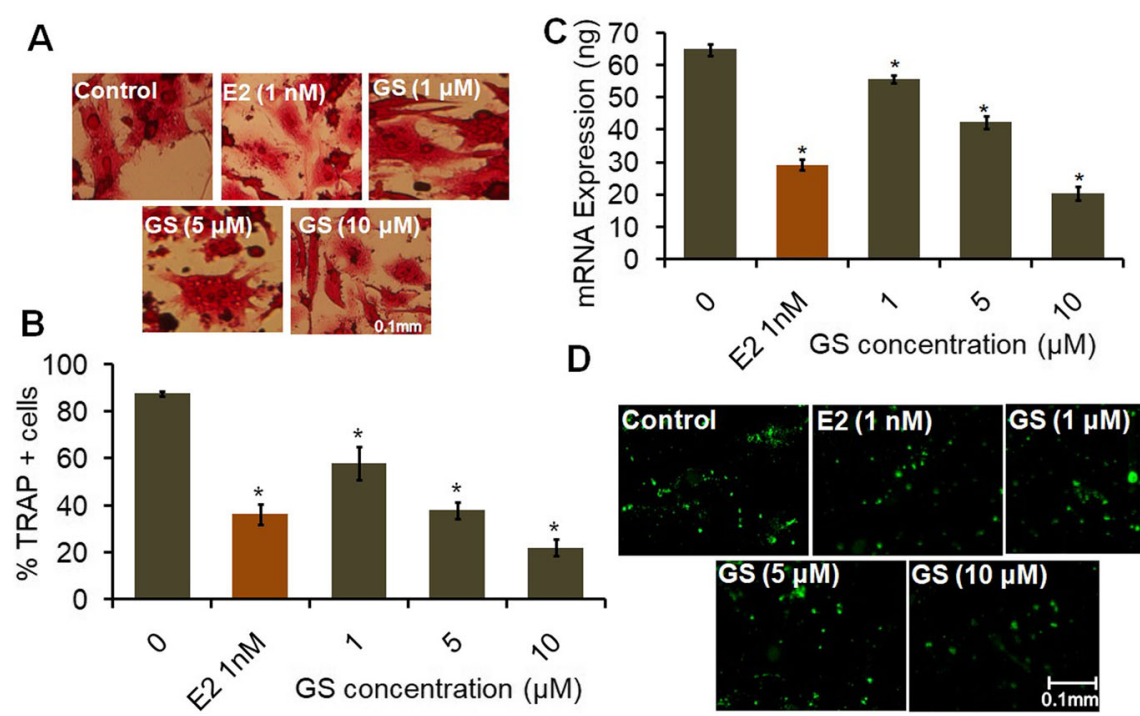

Fig. 6 Inhibition of osteoclastogenesis in bone marrow progenitor cells and the effect of GS on cathepsin K expression of osteoclasts. a Bone marrow stem cells were treated at 1,5 and $10 \mu \mathrm{M}$ concentrations of GS for 9 days in differentiation medium for osteoclast formation. $1 \mathrm{nM}$ of E2 was used as a positive control. Images were captured under a phase-contrast microscope. Scale bar =0.1 mm (b) The number of TRAP-positive multinucleated cells were scored and represented as \% TRAP-positive cells. Scale bar $=0.1 \mathrm{~mm}$. c Absolute qPCR analysis for cathepsin $\mathrm{K}$ mRNAs expression (d) Immunofluorescence stain of cathepsin K. Values are expressed as mean \pm SEM $(n=3) ;{ }^{*} P<0.05$ compared with control

number of cells in $\mathrm{S}$ phase of cell cycle [33]. Thus, the present study furnishes satisfactory evidence that the accumulation of DNA in S phase may be a marker of cell proliferation.

Oxidative stress is characterized by high level of intracellular ROS production which disrupts the balance of the redox system [34]. Various studies have proved that ROS induces oxidative stress and plays a key modulator of bone cell function and regulator of bone pathophysiology $[35,36]$. Isoflavone GS is known for its antioxidant activity in biological systems [37]. Interestingly, our data revealed that GS significantly inhibited the oxidantinduced overproduction of ROS in osteoblasts. In agreement with our results, a previous study has indicated that cordycepin, an active agent of Cordyceps militaris, displays antioxidant activity and prevents oxidative stress-induced inhibition of bone cell formation [38]. Similarly, an antioxidant fullerol has shown an osteogenesis promoting effect on human adipose-derived stem cells [39]. A recent study has reported the antioxidant effects of vitamin D3 under oxidative stress conditions which has been found to enhance the osteogenic differentiation of mesenchymal stem cells [40]. From these studies, it can be concluded that oxidative stress could be an important therapeutic target for bone cell remodeling and its associated function.

Osteogenesis is a well regulated process of osteoblasts and the factors generated by them could be used as indicators of various developmental stages. The most commonly used markers of osteoblast differentiation are alkaline phosphatase, Runx2, BMP2 and osteocalcin [41]. Quantitative real-time PCR analysis has shown that GS induces osteoblast differentiation by increasing the expression level of Runx2, BMP2 and osteocalcin genes (Fig. 5). Flavonoids are structurally very similar to estrogen and, therefore, they display strong estrogen-like activities. Hence, soy isoflavone genistein can be utilized as a substituent of estrogen. Because of its estrogen- like nature, GS may upregulate expression of ALP and collagen genes, and consequently, the expression level of Runx2 gene in osteoblasts. Runx2 is a non-collagenous key transcription factor regulating matrix mineralization of osteoblasts. Likewise, BMP2 gene regulates mineralization of osteoblasts and bone-specific alkaline phosphatase. Interestingly, a recent study has shown that active ingredients such as flavonoids, glycosides, terpenoids and phenols display estrogen-like biological activities, specifically affecting bone formation by regulating bone-specific matrix proteins (OCN, OPN, ALP, COL1), various transcription factors (Runx2, Osx, Cbfa1) and signaling pathways (BMP, MAPK) of osteoblasts [42]. Moreover, this study also shows that GS decreases osteoclastogenesis by reducing osteoclasts differentiation (Fig. 6). A previous study has shown that GS inhibits osteoclast differentiation by inhibiting the expression of TRAP, RANK, and calcitonin receptor in RAW 264.7 cell line [43]. Another study has found that aldehydic components of cinnamon bark extract strongly inhibits osteoclastic activity due to its estrogenic nature [44]. A recent study has also shown that flavonol herbacetin 
prevents formation and differentiation of osteoclasts with a decrease in the expression of RANK, TRAP, and cathepsin $\mathrm{K}$ in murine macrophage RAW264.7 cell line and bone marrow-derived macrophage cells [45]. These results have been found to be in agreement with the findings of the present study. Hence, the present study confirms the inhibitory mechanism of GS on osteoclast differentiation. These findings suggest that intake of GS isoflavone may be useful in bone health maintenance through osteoblastogenesis and osteoclast modulation.

\section{Conclusions}

The present study highlighted the osteogenic efficacy of GS via its antioxidant effect and S-phase elevation in primary osteoblasts along with anti-osteoclastogenic effect against bone-marrow-derived osteoclasts. This study makes a significant contribution in unraveling the novel role(s) of GS in imparting protective effects against oxidative stress-induced bone loss and particularly, in the regulation of bone remodeling. Further studies are needed to validate GS as a potential therapeutic candidate and regenerative medicine for the treatment of agerelated osteoporosis in humans.

\section{Supplementary information}

Supplementary information accompanies this paper at https://doi.org/10. 1186/s12906-020-03065-5.

Additional file 1 .

\section{Abbreviations}

GS: Genistein; SD: Sprague dawley; M-CSF: Macrophage colony stimulating factor; RANKL: Receptor activator of nuclear factor kappa-B ligand; TRAP: Tartrate-resistant acid phosphatase; DCFH-DA: Dichloro-dihydrofluorescein diacetate; Runx2: Runt-related transcription factor 2; BMP2: bone morphogenetic proteins 2; FBS: Fetal bovine serum; a-MEM: Alpha modification minimum essential medium; ALP: Alkaline phosphatase; pNPP: Para-nitro phenyl phosphate; qPCR: Quantitative polymerase chain reaction; $B S A$ : Bovine serum albumin

\section{Acknowledgments}

Sahabjada Siddiqui acknowledges to ICMR, New Delhi, India as a Research Associateship award (IRIS ID No. 2013-16160; File No. 45/26/2013/BMS/TRM). We would like to express our thanks to Mr. A.L. Vishwakarma, SAIF-Division, CSIR-CDRI for flow cytometry assistance and CSIR-IITR, Lucknow for ROS measurement. We acknowledge Department of Zoology, University of Lucknow and Department of Biotechnology, Era University, Lucknow for laboratory work and instrumentation facilities.

\section{Authors' contributions}

MA and AAM conceived the study. SS and MA analyzed and interpreted the data. SS performed the experiments. SS and MA wrote the manuscript. All authors have read and approved the manuscript.

\section{Funding}

Not applicable.

\section{Availability of data and materials}

The datasets used and analyzed in the current study are included in this article.

\section{Ethics approval and consent to participate}

All protocols and procedures employed were ethically reviewed and approved by Institutional Animal Ethics Committee of Azad Institute of Pharmacy and Research, Lucknow, India.

Consent for publication

Not applicable.

\section{Competing interests}

Sahabjada Siddiqui is an Editorial Board Member. All other authors have no competing interests.

\section{Author details}

'Department of Biotechnology, Era's Lucknow Medical College \& Hospital, Era University, Lucknow 226003, India. ${ }^{2}$ Department of Zoology, University of Lucknow, Lucknow 226007, India. ${ }^{3}$ Department of Biochemistry, King George's Medical University, Lucknow 226003, India. ${ }^{4}$ Department of Zoology, Aligarh Muslim University, Aligarh 202002, India.

Received: 26 March 2020 Accepted: 30 August 2020

Published online: 11 September 2020

References

1. Raggatt $L$, Partridge NC. Cellular and molecular mechanisms of bone remodeling. J Biol Chem. 2010;285:25103-8.

2. Dontas IA, Yiannakopoulos CK. Risk factors and prevention of osteoporosisrelated fractures. J Musculoskelet Neuronal Interact. 2007;7:268-72.

3. Kanis JA. World Health Organization Scientific Group. In: WHO technical report. UK: University of Sheffield; 2007. p. 66.

4. Akkawi I, Zmerly H. Osteoporosis: current concepts. Joints. 2018;6:122-7.

5. Kling JM, Clarke BL, Sandhu NP. Osteoporosis prevention, screening, and treatment: a review. J Women's Health. 2014;23:563-72.

6. Lees BA, Stevenson JC. The prevention of osteoporosis using sequential low-dose hormone replacement therapy with estradiol-17 $\beta$ and dydrogesterone. Osteoporos Int. 2001;12:251-8.

7. Weaver CM, Alekel DL, Ward WE, Ronis MJ. Flavonoid intake and bone health. J Nutr Gerontol Geriatr. 2012;31:239-53.

8. Song SH, Zhai YK, Li CQ, Yu Q, Lu Y, Zhang Y, et al. Effects of total flavonoids from Drynariae Rhizoma prevent bone loss in vivo and in vitro. Bone Rep. 2016;5:262-73.

9. Panche AN, Diwan AD, Chandra SR. Flavonoids: an overview. J Nutr Sci. 2016;5:e47.

10. Singh P, Kumar R, Sabapathy SN, Bawa AS. Functional and edible uses of soy protein products. Compr Rev Food Sci Food Saf. 2008;7:14-28.

11. Messina MJ, Wood CE. Soy isoflavones, estrogen therapy, and breast cancer risk: analysis and commentary. Nutr J. 2008;7:17.

12. Shi W, Gao Y, Wang Y, Zhou J, Wei Z, Ma X, et al. The flavonol glycoside icariin promotes bone formation in growing rats by activating the CAMP signaling pathway in primary cilia of osteoblasts. J Biol Chem. 2017;292: 20883-96.

13. Su Y, Chen Y, Liu Y, Yang Y, Deng Y, Gong Z, et al. Antiosteoporotic effects of Alpinia officinarum Hance through stimulation of osteoblasts associated with antioxidant effects. J Orthop Translat. 2016;4:75-91.

14. Shim KS, Lee B, Ma JY. Water extract of Rumex crispus prevents bone loss by inhibiting osteoclastogenesis and inducing osteoblast mineralization. BMC Complement Altern Med. 2017;17:483.

15. Siddiqui $\mathrm{S}$, Arshad M. Osteogenic potential of punica granatum through matrix mineralization, cell cycle progression and runx2 gene expression in primary rat osteoblasts. Daru. 2014;22:72.

16. Omeje EO, Khan MP, Osadebe PO, Tewari D, Khan MF, Dev K, et al. Analysis of constituents of the eastern Nigeria mistletoe, Loranthus micranthus Linn revealed presence of new classes of osteogenic compounds. J Ethnopharmacol. 2014;151:643-51.

17. Filipović B, Šošić-Jurjević B, Ajdžanović V, Živanović J, Manojlović-Stojanoski $M$, Nestorović $N$, et al. The phytoestrogen genistein prevents trabecular bone loss and affects thyroid follicular cells in a male rat model of osteoporosis. J Anat. 2018:233:204-12.

18. Chen C, Zheng H, Qi S. Genistein and silicon synergistically protects against ovariectomy-induced bone loss through upregulating OPG/RANKL ratio. Bio Trace Elem Res. 2019;188:441-50. 
19. Bhattarai G, Poudel SB, Kook SH, Lee JC. Anti-inflammatory, anti-osteoclastic, and antioxidant activities of genistein protect against alveolar bone loss and periodontal tissue degradation in a mouse model of periodontitis. J Biomed Mater Res A. 2017;105:2510-21.

20. Lee SH, Kim JK, Jang HD. Genistein inhibits osteoclastic differentiation of RAW 264.7 cells via regulation of ROS production and scavenging. Int J Mol Sci. 2014;15:10605-21.

21. Khan $K$, Singh A, Mittal M, Sharan $K$, Singh N, Dixit $P$, et al. Gingerol induces bone loss in ovary intact adult mice and augments osteoclast function via the transient receptor potential vanilloid 1 channel. Mol Nutr Food Res. 2012;56:1860-73.

22. Siddiqui S, Ahmad E, Gupta M, Rawat V, Shivnath N, Banerjee M, et al. Cissus quadrangularis Linn exerts dose-dependent biphasic effects: osteogenic and anti-proliferative, through modulating ROS, cell cycle and Runx2 gene expression in primary rat osteoblasts. Cell Prolif. 2015;48:443-54.

23. Wu S, Xiao Z, Song J, Li M, Li W. Evaluation of BMP-2 enhances the osteoblast differentiation of human amnion mesenchymal stem cells seeded on nano-hydroxyapatite/collagen/poly (I-lactide). Int J Mol Sci. 2018; 19:2171.

24. Goto T, Hagiwara K, Shirai N, Yoshida K, Hagiwara H. Apigenin inhibits osteoblastogenesis and osteoclastogenesis and prevents bone loss in ovariectomized mice. Cytotechnology. 2015;67:357-65.

25. Hou WS, Li W, Keyszer G, Weber E, Levy R, Klein MJ, et al. Comparison of cathepsins $\mathrm{K}$ and $\mathrm{S}$ expression within the rheumatoid and osteoarthritic synovium. Arthritis Rheumatism. 2002;46:663-74.

26. Pan W, Quarles LD, Song LH, Yu YH, Jiao C, Tang HB, et al. Genistein stimulates the osteoblastic differentiation via NO/cGMP in bone marrow culture. J Cell Biochem. 2005;94:307-16.

27. Wang S, Fu Y, Zhao XH. The cooperative effect of genistein and protein hydrolysates on the proliferation and survival of osteoblastic cells (hFOB 1. 19). Molecules. 2016;21:1489.

28. Nishide $Y$, Tousen $Y$, Tadaishi M, Inada M, Miyaura C, Kruger M, et al. Combined effects of soy isoflavones and $\beta$-carotene on osteoblast differentiation. Int J Environ Res Public Health. 2015;12:13750-61.

29. Guo AJ, Choi RC, Cheung AW, Chen VP, Xu SL, Dong TT, et al. Baicalin, a flavone, induces the differentiation of cultured osteoblasts an action via the Wnt/ $\beta$-catenin signaling pathway. J Biol Chem. 2011;286:27882-93.

30. Price KM, Muirhead KA, Wallace PK. Proliferation by many other names: monitoring cell cycle progression and cell division by flow cytometry. Cytometry A. 2016;89:233.

31. Ikegami AK, Inoue SA, Hosoi TA, Kaneki MA, Mizuno YU, Akedo YO, et al. Cell cycle-dependent expression of estrogen receptor and effect of estrogen on proliferation of synchronized human osteoblast-like osteosarcoma cells. Endocrinology. 1994;135:782-9.

32. Lin JH, Deng LX, Wu ZY, Chen L, Zhang L. Pilose antler polypeptides promote chondrocyte proliferation via the tyrosine kinase signaling pathway. J Occup Med Toxicol. 2011;6:27.

33. Fu C, Zheng C, Lin J, Ye J, Mei Y, Pan C, et al. Cibotium barometz polysaccharides stimulate chondrocyte proliferation in vitro by promoting G1/S cell cycle transition. Mol Med Rep. 2017;15:3027-34.

34. Wauquier F, Leotoing L, Coxam V, Guicheux J, Wittrant Y. Oxidative stress in bone remodelling and disease. Trends Mol Med. 2009;15:468-77.

35. Filaire $\mathrm{E}$, Toumi $\mathrm{H}$. Reactive oxygen species and exercise on bone metabolism: friend or enemy? Joint Bone Spine. 2012;79:341-6.

36. Schieber $M$, Chandel NS. ROS function in redox signaling and oxidative stress. Curr Biol. 2014;24:R453-62.

37. Arora A, Nair MG, Strasburg GM. Antioxidant activities of isoflavones and their biological metabolites in a liposomal system. Arch Biochem Biophys. 1998;356:133-41.

38. Wang F, Yin P, Lu Y, Zhou Z, Jiang C, Liu Y, et al. Cordycepin prevents oxidative stress-induced inhibition of osteogenesis. Oncotarget. 2015;6: 35496.

39. Yang X, Li CJ, Wan Y, Smith P, Shang G, Cui Q. Antioxidative fullerol promotes osteogenesis of human adipose-derived stem cells. Int $J$ Nanomedicine. 2014;9:4023.

40. Zhou J, Wang F, Ma Y, Wei F. Vitamin D3 contributes to enhanced osteogenic differentiation of MSCs under oxidative stress condition via activating the endogenous antioxidant system. Osteoporos Int. 2018;29: $1917-26$.
41. Hoeppner LH, Secreto F, Jensen ED, Li X, Kahler RA, Westendorf JJ. Runx2 and bone morphogenic protein 2 regulate the expression of an alternative Lef1 transcript during osteoblast maturation. J Cell Physiol. 2009;221:480-9.

42. An J, Yang H, Zhang Q, Liu C, Zhao J, Zhang L, et al. Natural products for treatment of osteoporosis: the effects and mechanisms on promoting osteoblast-mediated bone formation. Life Sci. 2016;147:46-58.

43. Bandyopadhyay S, Lion JM, Mentaverri R, Ricupero DA, Kamel S, Romero JR, et al. Attenuation of osteoclastogenesis and osteoclast function by apigenin. Biochem Pharmacol. 2006;72:184-97.

44. Tsuji-Naito K. Aldehydic components of cinnamon bark extract suppresses RANKL-induced osteoclastogenesis through NFATC1 downregulation. Bioorg Med Chem. 2008;16:9176-83.

45. Li L, Sapkota M, Kim SW, Soh Y. Herbacetin inhibits RANKL-mediated osteoclastogenesis in vitro and prevents inflammatory bone loss in vivo. Eur J Pharmacol. 2016;777:17-25

\section{Publisher's Note}

Springer Nature remains neutral with regard to jurisdictional claims in published maps and institutional affiliations.

Ready to submit your research? Choose BMC and benefit from:

- fast, convenient online submission

- thorough peer review by experienced researchers in your field

- rapid publication on acceptance

- support for research data, including large and complex data types

- gold Open Access which fosters wider collaboration and increased citations

- maximum visibility for your research: over $100 \mathrm{M}$ website views per year

At BMC, research is always in progress.

Learn more biomedcentral.com/submissions 